\title{
Modular and smooth introduction of photonics in high-throughput communication satellites - perspective of project BEACON
}

SDE. Vanessa C. Duartea,b, João G. Prataa, Rogério N. Nogueiraa,c, Georg Winzer ${ }^{b}$, Lars Zimmermann ${ }^{b}$, Rob Walker ${ }^{d}$, Stephen Clements ${ }^{d}$, Marta Filipowicz ${ }^{\circ}$, Marek Napierała ${ }^{e}$, Tomasz Nasilowski ${ }^{\ominus}$, Jonathan Crabb $^{f}$, Leontios Stampoulidis ${ }^{f}$, Javad Anzalchig and Miguel V. Drummond ${ }^{a}$

a Instituto de Telecomunicaçōes, Aveiro, Portugal $\quad$ d aXenic Ltd., Sedgefield, UK $\quad$ 9Airbus Defence \& Space, Stevenage, UK

\section{INTRODUCTION}
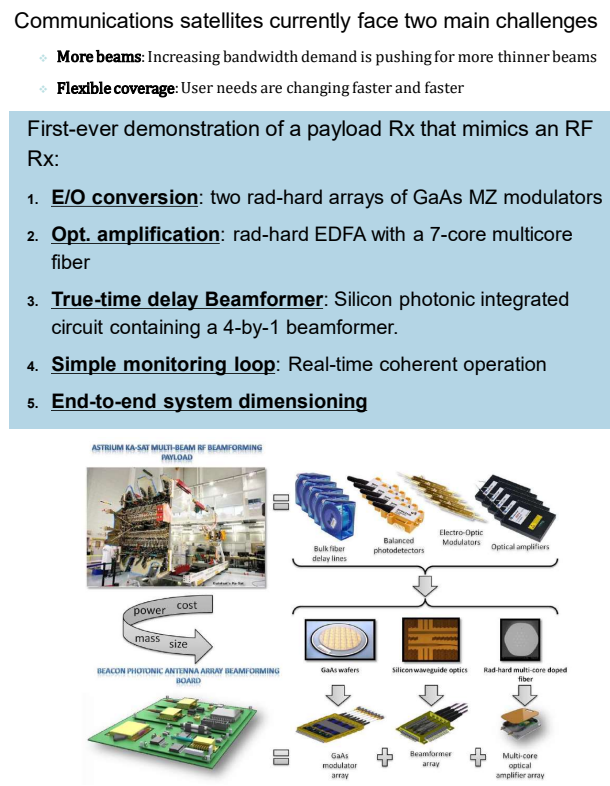

Fig. 1 BEACON concept.

\section{EXPERIMENT}

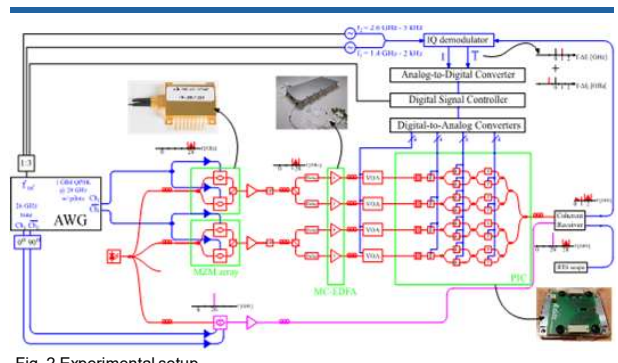

Fig. 2 Experimental setup

\section{PIC layout}

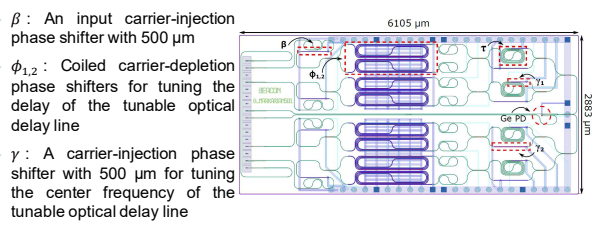

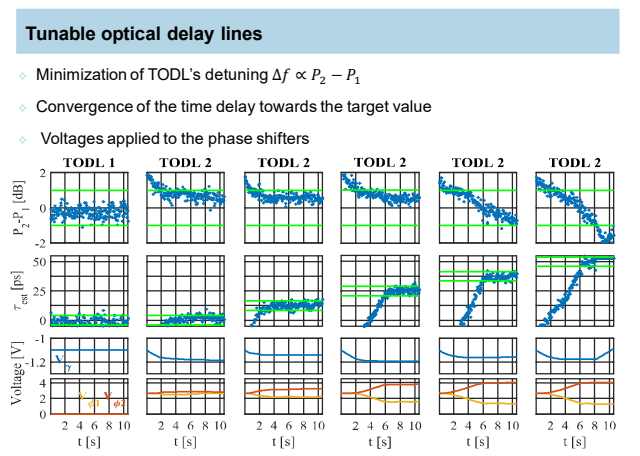

Real-time beamforming

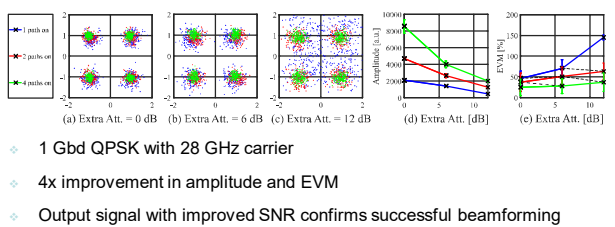

END-TO-END SYSTEM DIMENSIONING

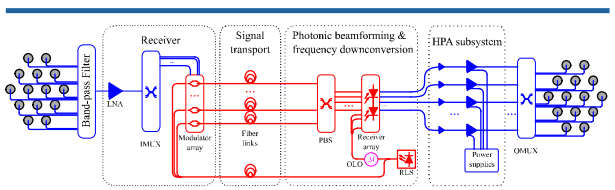

Fig. 3 Scheme of the proposed receiving stage.
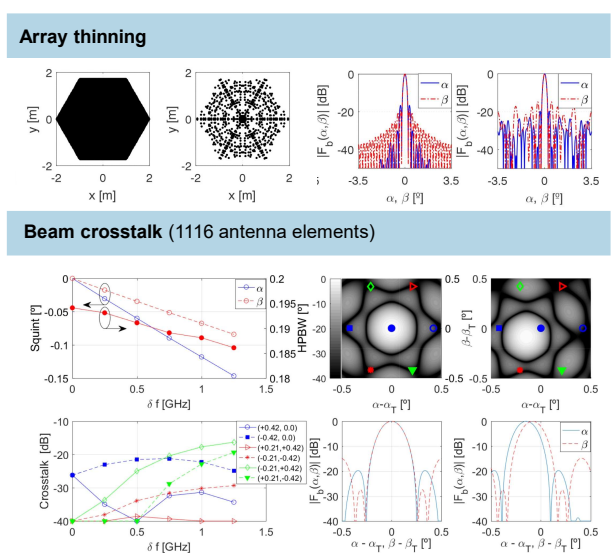
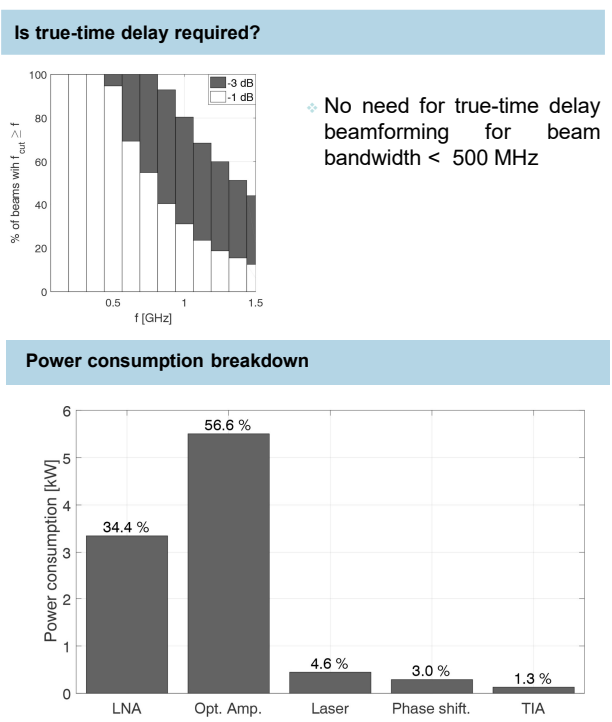

SNR, power consumption and beam crosstalk vs. of the number of antenna elements

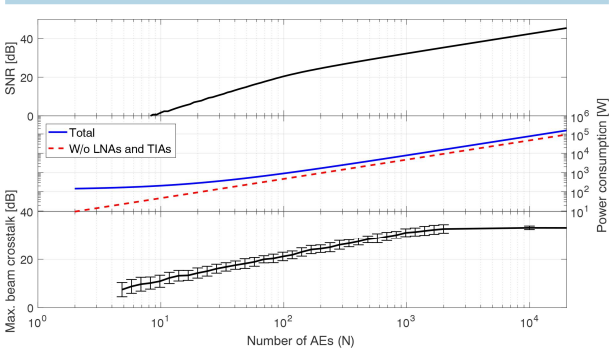

For commonly used 100 antenna elements:

SNR of $20 \mathrm{~dB}$

Beam crosstalk of $21 \mathrm{~dB}$

Power consumption of $900 \mathrm{~W}: 70 \%$ of which consumed by photonic devices

\section{PATENTS}

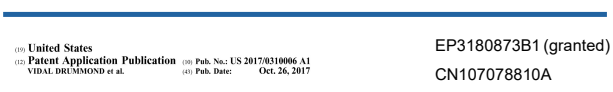

\section{ACKNOWLEDGEMENTS}

The authors would like to acknowledge financial support from European Commission through the projects BEACON (FP7-SPACE-2013-1-607401); $\begin{array}{llll}\text { European Regional Development } & \text { Fund } & \text { (ERDF) (FEDER) }\end{array}$ (UID/EEA/50008/2013). 